\title{
Rate of Kidney Function Decline in Older Adults: A Comparison Using Creatinine and Cystatin C
}

\author{
Michael G. Shlipak ${ }^{a}$ Ronit Katz ${ }^{b}$ Bryan Kestenbaum ${ }^{c}$ Linda F. Fried $^{d}$

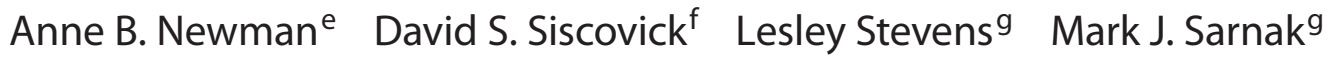 \\ ${ }^{a}$ General Internal Medicine Section, San Francisco VA Medical Center and Departments of Medicine, Epidemiology \\ and Biostatistics, University of California, San Francisco, Calif., ${ }^{b}$ Collaborative Health Studies Coordinating Center, \\ Department of Biostatistics, University of Washington, and ${ }^{\mathrm{C} N e p h r o l o g y}$ Division, University of Washington, \\ School of Medicine, Seattle, Wash., dRenal Section, Medical Service, VA Pittsburgh Healthcare System, and \\ e Department of Epidemiology, University of Pittsburgh Graduate School of Public Health and the Division of \\ Geriatric Medicine, University of Pittsburgh School of Medicine, Pittsburgh, Pa., ${ }^{f}$ Departments of Medicine and \\ Epidemiology, University of Washington, Seattle, Wash., and ${ }^{9}$ Division of Nephrology, Department of Medicine, \\ Tufts Medical Center, Boston, Mass., USA
}

\section{Key Words}

Glomerular filtration rate $\cdot$ Creatinine $\cdot$ Cystatin C $\cdot$

Chronic kidney disease

\begin{abstract}
Background/Aims: The aim of this study was to determine the decline in the estimated glomerular filtration rate (eGFR) in elderly persons and to compare estimates based on creatinine and cystatin C. Methods: In the Cardiovascular Health Study, GFR changes in an elderly cohort were estimated from serum creatinine and cystatin $C$ measured at baseline, year 3 and year 7 in 4,380 participants (age $72 \pm 5$ years at entry). Outcomes were mean eGFR decline, incident chronic kidney disease (CKD) and rapid decline in eGFR (annual loss $>3 \mathrm{ml} /$ $\mathrm{min} / 1.73 \mathrm{~m}^{2}$ ). Results: Mean annual eGFR loss as estimated from creatinine was $0.4 \pm 3.6 \mathrm{ml} / \mathrm{min} / 1.73 \mathrm{~m}^{2}$, with $16 \%$ of the participants experiencing a rapid decline. Mean eGFR loss as estimated from cystatin C was $1.8 \pm 2.6$, with $25 \%$ of the participants experiencing a rapid decline $(p<0.001$ for both). Among participants without baseline CKD, incident CKD was detected at year 7 in $10 \%(n=263)$ using creatinine and $19 \%(n=544)$ using cystatin $C(p<0.001)$. Increasing age
\end{abstract}

was the strongest predictor of rapid decline; adjusted odds ratios were 1.38 (1.16-1.65), $1.62(1.31-1.99)$ and 2.96 (2.283.84) for participants aged $70-74,75-79$ and $80+$ at baseline, compared with those aged 65-69. Conclusion: In elderly persons, cystatin C estimated substantially larger declines in kidney function than creatinine did. Defining the optimal measurement of kidney function in elderly persons should be a high priority for future research.

Copyright $\odot 2009$ S. Karger AG, Basel

\section{Introduction}

Impaired kidney function is highly prevalent in the elderly and is a risk factor for cardiovascular disease, adverse health outcomes and death. Because kidney function is a major determinant of health in the elderly, it is important to understand the expected rate of change in kidney function. However, the rate at which kidney function declines in elderly persons and the independent effects of age, sex and race have not been conclusively studied. Based on findings using creatinine clearance among a healthy, predominately white cohort (Baltimore Longi-

\section{KARGER}

(C) 2009 S. Karger AG, Basel

Fax +41613061234 E-Mail karger@karger.ch www.karger.com www.karger.com/ajn
Michael G. Shlipak, MD, MPH

General Internal Medicine Section, VA Medical Center (111Al)

4150 Clement Street

San Francisco, CA 94121 (USA)

Tel. +1 415750 2093, Fax +1 415379 5573,E-Mail michael.shlipak@ucsf.edu 
tudinal Study of Aging), age-related decline in glomerular filtration rate (GFR) is generally believed to be less than $1 \mathrm{ml} / \mathrm{min} / 1.73 \mathrm{~m}^{2}$ each year [1]. To understand longitudinal changes in kidney function among elderly persons, we ideally would use a 'gold standard' measure of GFR across many years of follow-up. Unfortunately, few studies have directly measured GFR in elderly persons, and none have repeated GFR measurements after several years of follow-up. The use of endogenous filtration markers, particularly creatinine, to estimate declines in kidney function is thus the current standard for clinical practice and research.

Creatinine-based measurements of kidney function, however, may be limited as a tool to estimate either the rate of kidney function change in the elderly or the effects of age, sex and race. Since creatinine is a breakdown product of muscle, serum creatinine levels are directly associated with muscle mass. Muscle mass is lower in older persons, women and whites on average, which complicates the interpretation of creatinine changes over time. Equations to estimate GFR from creatinine make the inherent assumption that the effects of age, sex and race on the creatinine-GFR relationship are constant over time. Cystatin $\mathrm{C}$ is an alternative serum marker of kidney function that appears less biased for measuring kidney function in the elderly. Prior studies using cystatin C in older persons demonstrated its greater prognostic ability compared with creatinine or creatinine-based estimated GFR (eGFR) for predicting adverse outcomes [2-7]. Yet, no study has evaluated changes in kidney function over time using cystatin $\mathrm{C}$, or compared such changes with estimates based on creatinine.

In the Cardiovascular Health Study (CHS), we serially measured cystatin $\mathrm{C}$ and creatinine. We recently found that participants with rapid declines in eGFR $(>3 \mathrm{ml} /$ $\mathrm{min} / 1.73 \mathrm{~m}^{2}$ per year), based on either creatinine or cystatin $\mathrm{C}$, had substantially elevated mortality risks during follow-up independent of baseline kidney function and other comorbidities [8]. In this paper, we compared changes in kidney function over 7 years of follow-up using GFR estimates based on creatinine and cystatin C. In addition, we evaluated the associations of age, sex and race (white or black) on kidney disease progression.

\section{Methods}

\section{Study Design}

The CHS is a community-based longitudinal study of adults who were 65 years of age or older at baseline [9]. A main cohort of 5,201 participants was recruited between 1989 and 1990 from 4
US communities (Sacramento County, Calif., USA; Forsyth County, N.C., USA; Washington County, Md., USA; Allegheny County, Pa., USA) [10]. An additional 687 African-Americans were recruited in 1992 and 1993. The baseline visit for these additional participants was the year 3 visit for the original cohort. Eligible participants were sampled from Medicare eligibility lists in each area. Subjects were excluded if they were institutionalized, required a proxy to give consent, were planning to move out of the area within 3 years after recruitment, required a wheelchair in the home, were receiving hospice care, or were undergoing radiation or chemotherapy for cancer.

Institutional review board approval for the data collection procedures of the CHS was obtained at each of the 4 clinical sites and at the Data Coordinating Center (University of Washington). In addition, we obtained institutional review board approval for this study from Tufts-New England Medical Center and the University of California, San Francisco, Calif., USA.

\section{Measurements of Kidney Function}

Participants were included if they had at least 2 measurements of kidney function using both creatinine and cystatin $\mathrm{C}$ ( $\mathrm{n}=$ 4,$380 ; 2,396$ participants had 3 measurements of kidney function and 1,984 participants had 2 measurements; 1,452 had only 1 measurement of kidney function). Cystatin C was measured from frozen samples that were collected at visits from 1989-1990 (baseline), 1992-1993 (3rd year of follow-up) and 1996-1997 (7th year of follow-up) using a BNII nephelometer (Siemens; Deerfield, Ill., USA) [11]. The year 3 measurements were conducted in 2003, and the baseline and year 7 measurements in 2006. All measurements used the same equipment in the same laboratory. Cystatin $\mathrm{C}$ remained stable through five cycles of freeze/thaw [6]. We estimated GFR from cystatin C using an equation developed from the pooling of several cohorts with GFR measured from iothalamate $\left(\mathrm{eGFR}=76.7 \times \mathrm{cysC}^{-1.18}\right)[12]$. As a sensitivity analysis, we repeated the analyses using 100/cystatin C as the index of kidney function, as used in prior literature [13].

Serum creatinine was assayed by a colorimetric method (Ektachem 700, Eastman Kodak) from frozen sera. We estimated GFR with the use of the 4-variable version of the Modification of Diet in Renal Disease equation [GFR $=186.3 \times$ (serum creatinine $\left.\mathrm{e}^{-1.154}\right) \times\left(\right.$ age $\left.^{-0.203}\right) \times 1.212$ (if black) $\times 0.742$ (if female) $]$, updating age for each creatinine measurement [14]. Results were very similar when age was held constant through the analyses. Creatinine concentrations were indirectly calibrated to the reference laboratory at the Cleveland Clinic, as previously described [15].

\section{Predictors of Kidney Function Decline}

Age, sex and race were the primary predictors in this analysis. Additional predictors of kidney decline were used for adjustment in multivariate analysis. These included prevalent cardiovascular disease [heart failure, coronary heart disease (myocardial infarction, angina, revascularization), stroke and transient ischemic attack], hypertension, diabetes mellitus (defined by use of an oral hypoglycemic agent, insulin or a fasting glucose level $\geq 126 \mathrm{mg} / \mathrm{dl}$ ), body mass index, smoking history (former vs. never, current vs. never), and fasting levels of low-density lipoprotein cholesterol and high-density lipoprotein cholesterol. Models were similar when systolic or diastolic blood pressure measurements were used.

We compared the characteristics of participants with and without at least 2 measurements of kidney function. Among par- 
ticipants with multiple measurements, characteristics of white women, black women, white men and black men were compared by ANOVA and a $\chi^{2}$ test as appropriate.

As the length of follow-up varied among participants, change in kidney function was determined by linear regression as the slope per year for each individual. Mixed models were used in supplementary analyses, which produced identical results. We confirmed that the annual rate of increase in creatinine and cystatin $\mathrm{C}$ was equivalent across each time interval. We compared the distribution of the rates of decline using GFR estimated from creatinine $\left(\mathrm{eGFR}_{\text {crea }}\right)$ and GFR estimated from cystatin $\mathrm{C}$ $\left(e G F R_{c y s}\right)$, and determined the proportions with a net decline in eGFR, a rate of decline $>1$ and $>3 \mathrm{ml} / \mathrm{min} / 1.73 \mathrm{~m}^{2} /$ year. A rate of decline $>3 \mathrm{ml} / \mathrm{min} / 1.73 \mathrm{~m}^{2} /$ year was defined as 'rapid kidney decline' based on prior studies and its concurrence with the high quartile of $\mathrm{eGFR}_{\text {cys }}$ decline $[8,16-18]$. This rate of kidney function decline was associated with higher rates of mortality during subsequent follow-up in CHS, whereas no association was observed below the threshold of $3 \mathrm{ml} / \mathrm{min} /$ year [8].

We compared the annual rates of kidney function decline across age categories $(65-69,70-74,75-79,>80$ years) and among the 4 sex/race categories. We created linear regression models that modeled the annual rate of change in eGFR $\mathrm{crea}_{\text {or }} \mathrm{GFR}_{\mathrm{cys}}$ as the dependant variable in separate models adjusted for the covariates listed above. Sidak-adjusted tests for significance were used to evaluate differences in mean levels among sex and race groups [19]. Multivariate logistic regression was used to evaluate age, sex and race as independent predictors of the dichotomized outcome: rapid kidney function decline.

Among participants without chronic kidney disease (CKD; eGFR $>60 \mathrm{ml} / \mathrm{min} / 1.73 \mathrm{~m}^{2}$ ) at the baseline visit, we compared the incidence of CKD $\left(e G F R<60 \mathrm{ml} / \mathrm{min} / 1.73 \mathrm{~m}^{2}\right)$ at the final measurement of kidney function using creatinine and cystatin C. In these analyses, baseline $\mathrm{CKD}$ and incident $\mathrm{CKD}$ were determined separately using creatinine and cystatin $\mathrm{C}$. In addition, the incidence of eGFR $<45 \mathrm{ml} / \mathrm{min} / 1.73 \mathrm{~m}^{2}$, which has been referred to as stage $3 \mathrm{~B}$ CKD [20], was also compared using creatinine and cystatin C. Incidence of end-stage renal disease (ESRD) was too low during follow-up to evaluate this outcome. As a sensitivity analysis, we evaluated the combined outcome of 'death or CKD' to capture participants who died prior to having a second measurement of kidney function. The associations of $\mathrm{eGFR}_{\text {crea }}$ and $\mathrm{eGFR}_{\text {cys }}$ with this combined endpoint were compared.

S-Plus (release 8.0; Insightful Inc., Seattle, Wash., USA) and SPSS statistical software (release 15.0.1.1; SPSS Inc., Chicago, Ill., USA) were used for the analyses. $\mathrm{p}<0.05$ was considered statistically significant.

\section{Results}

Compared with participants with $0-1$ measurements of kidney function, those with at least 2 measurements of kidney function were younger (72 vs. 76 years), more likely to be white ( 86 vs. $77 \%$ ), female (60 vs. $52 \%$ ) and had lower creatinine levels at baseline $(0.93 \pm 0.30$ vs. $1.07 \pm$ $0.61 \mathrm{mg} / \mathrm{dl}$ ) ( $\mathrm{p}$ for all comparisons <0.001). Among participants with $0-1$ measurements, $51 \%$ had died prior to the 1996-1997 clinical visit when the last kidney function measurement was to be attained.

\section{Characteristics of Included Participants}

Among participants with at least 2 measurements of creatinine and cystatin C, 2,234 were white women, 376 were black women, 1,561 were white men and 209 were black men. Average age was approximately 72 years in each subgroup. Cardiovascular risk factors, prevalent cardiovascular disease and measurements of kidney function differed across the sex/race subgroups (table 1). Baseline levels of cystatin $C$ were the highest, and $\mathrm{eGFR}_{\text {cys }}$ the lowest, among white men, but were similar among the other 3 groups. Serum creatinine levels were higher in black men than in white men, and higher in black women than in white women; however, black participants had higher $\mathrm{GFR}_{\text {crea }}$ than whites.

At baseline, the mean eGFR $\mathrm{crea}_{\text {and }}$ aGFR $\mathrm{Cry}_{\text {cys }}$ levels were the same for the cohort overall $(79 \pm 23$ and $79 \pm$ 19 , respectively) and within each demographic subgroup (table 1). At the final kidney measure, the mean eGFR was higher than eGFR cys $(78 \pm 23$ vs. $70 \pm 19 \mathrm{ml} / \mathrm{min} / 1.73$ $\left.\mathrm{m}^{2}, \mathrm{p}<0.001\right)$. The difference between the final eGFR estimates based on creatinine and cystatin $\mathrm{C}$ varied from $6 \mathrm{ml} / \mathrm{min} / 1.73 \mathrm{~m}^{2}$ in black women to $12 \mathrm{ml} / \mathrm{min} / 1.73 \mathrm{~m}^{2}$ in white men.

\section{Distribution of Change in Kidney Function}

The distribution of annual change in eGFR for the cohort differed greatly when comparing the equations based on creatinine and cystatin $\mathrm{C}$ (fig. 1). The distribution of annual $\mathrm{eGFR}_{\text {crea }}$ change appeared normal and centered near the origin. Thirty-nine percent of the cohort had a positive slope of $\mathrm{eGFR}_{\text {crea }}$ (improved kidney function over time). The mean annual change of eGFR $\mathrm{crea}_{\text {was a }}$ decline of $0.4 \pm 3.6 \mathrm{ml} / \mathrm{min} / 1.73 \mathrm{~m}^{2}$. Thirty-two percent had a net annual decline $\geq 1 \mathrm{ml} / \mathrm{min} / 1.73 \mathrm{~m}^{2} /$ year, and $16 \%$ had a decline $\geq 3 \mathrm{ml} / \mathrm{min} / 1.73 \mathrm{~m}^{2} /$ year. The distribution of annual change in $\mathrm{eGFR}_{\mathrm{cys}}$ also appeared normal, but only $20 \%$ had a positive slope. The mean change was an annual decline of $1.8 \pm 2.6 \mathrm{ml} / \mathrm{min} 1.73 \mathrm{~m}^{2}$. Sixtytwo percent had an annual decline $\geq 1 \mathrm{ml} / \mathrm{min} 1.73 \mathrm{~m}^{2}$ and $25 \%$ had a decline $\geq 3 \mathrm{ml} / \mathrm{min} 1.73 \mathrm{~m}^{2}(\mathrm{p}<0.001$ for both comparisons with $\mathrm{eGFR}_{\text {crea }}$ ). When we used 100/ cystatin $\mathrm{C}$ to estimate $\mathrm{GFR}_{\text {cys }}$, the mean annual decline was $2.0 \pm 2.9 \mathrm{ml} / \mathrm{min}$.

\section{Age and Loss of Kidney Function}

The rate of loss in kidney function appeared to accelerate among older participants. The annual decline in 

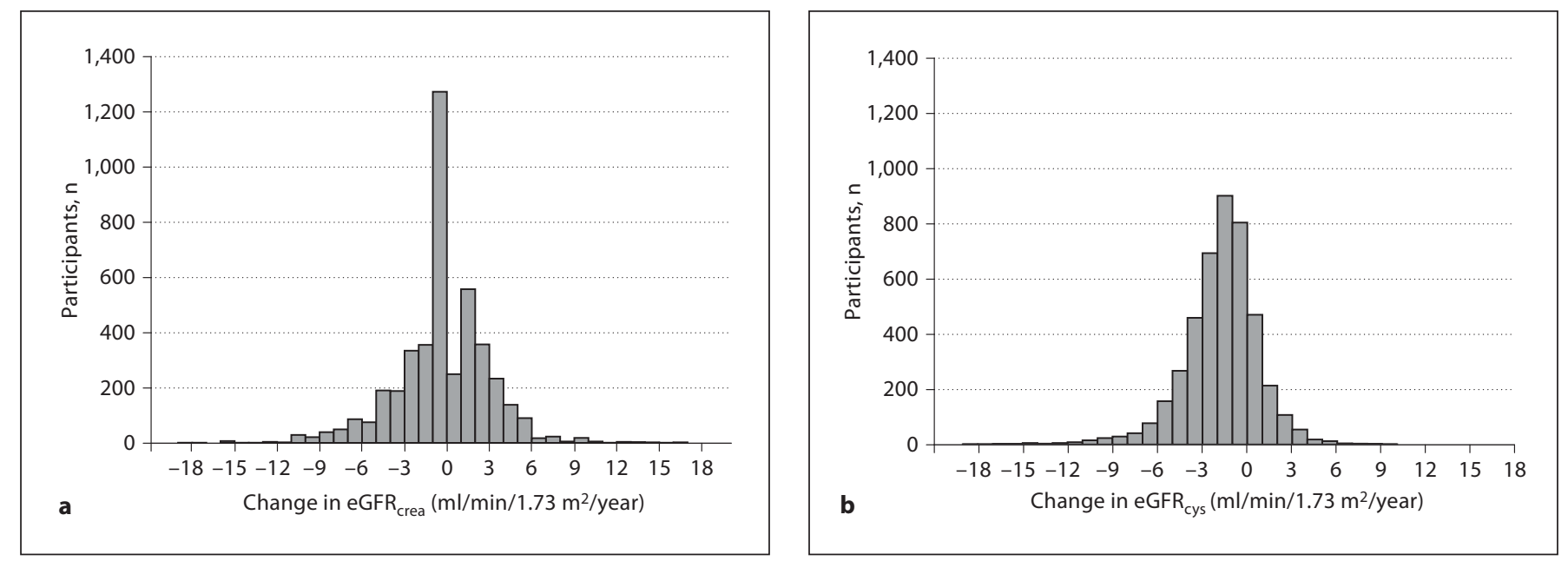

Fig. 1. Distribution of annual change in $\operatorname{eGFR}_{\text {crea }}(\mathbf{a})$ and $\operatorname{eGFR}_{\text {cys }}(\mathbf{b})$.

Table 1. Characteristics of the 4,380 participants from CHS

\begin{tabular}{|c|c|c|c|c|}
\hline & \multicolumn{2}{|l|}{ Women } & \multicolumn{2}{|l|}{ Men } \\
\hline & $\begin{array}{l}\text { white } \\
(\mathrm{n}=2,234)\end{array}$ & $\begin{array}{l}\text { black } \\
(\mathrm{n}=376)\end{array}$ & $\begin{array}{l}\text { white } \\
(\mathrm{n}=1,561)\end{array}$ & $\begin{array}{l}\text { black } \\
(n=209)\end{array}$ \\
\hline Age, years & $72 \pm 5$ & $72 \pm 5$ & $73 \pm 5$ & $72 \pm 5$ \\
\hline Diabetes & $244(11 \%)$ & $79(21 \%)$ & $242(16 \%)$ & $53(25 \%)$ \\
\hline Systolic blood pressure, mm Hg & $135 \pm 21$ & $143 \pm 23$ & $134 \pm 21$ & $140 \pm 21$ \\
\hline Diastolic blood pressure, $\mathrm{mm} \mathrm{Hg}$ & $69 \pm 11$ & $75 \pm 11$ & $72 \pm 11$ & $77 \pm 11$ \\
\hline LDL cholesterol, mg/dl & $135 \pm 36$ & $131 \pm 33$ & $124 \pm 33$ & $122 \pm 33$ \\
\hline HDL cholesterol, mg/dl & $59 \pm 16$ & $61 \pm 15$ & $47 \pm 12$ & $53 \pm 14$ \\
\hline Prevalent cardiovascular disease & $371(17 \%)$ & $90(24 \%)$ & $466(30 \%)$ & $56(27 \%)$ \\
\hline Baseline creatinine, $\mathrm{mg} / \mathrm{dl}$ & $0.80 \pm 0.23$ & $0.93 \pm 0.36$ & $1.09 \pm 0.26$ & $1.17 \pm 0.30$ \\
\hline Baseline cystatin C, mg/l & $1.00 \pm 0.24$ & $1.00 \pm 0.33$ & $1.07 \pm 0.24$ & $0.97 \pm 0.21$ \\
\hline Baseline $\mathrm{eGFR}_{\text {crea }}, \mathrm{ml} / \mathrm{min} / 1.73 \mathrm{~m}^{2}$ & $81 \pm 24$ & $83 \pm 24$ & $75 \pm 20$ & $85 \pm 23$ \\
\hline Baseline $\mathrm{eGFR}_{\text {cys }}, \mathrm{ml} / \mathrm{min} / 1.73 \mathrm{~m}^{2}$ & $81 \pm 32$ & $83 \pm 21$ & $75 \pm 17$ & $84 \pm 18$ \\
\hline Final eGFR ${ }_{\text {crea }}, \mathrm{ml} / \mathrm{min} / 1.73 \mathrm{~m}^{2}$ & $78 \pm 23$ & $80 \pm 24$ & $77 \pm 23$ & $85 \pm 26$ \\
\hline Final $\mathrm{eGFR}_{\text {cys }}, \mathrm{ml} / \mathrm{min} / 1.73 \mathrm{~m}^{2}$ & $71 \pm 19$ & $74 \pm 22$ & $65 \pm 17$ & $75 \pm 20$ \\
\hline
\end{tabular}

To convert conventional to SI units, multiply HDL and LDL cholesterol by 0.0259 for $\mathrm{mmol} / \mathrm{l}$, and multiply creatinine by 88.4 for $\mu \mathrm{mol} / \mathrm{l}$.

eGFR $_{\text {crea }}$ ranged from $0.1(0.09) \mathrm{ml} / \mathrm{min} / 1.73 \mathrm{~m}^{2}$ in the 65-69 age group to $0.8(0.18) \mathrm{ml} / \mathrm{min} / 1.73 \mathrm{~m}^{2}$ among those over 80 years $(\mathrm{p}<0.001)$. Kidney function loss by $\mathrm{eGFR}_{\text {cys }}$ also appeared to increase with advancing age, ranging from $1.6(0.06) \mathrm{ml} / \mathrm{min} / 1.73 \mathrm{~m}^{2} /$ year in the $65-$ 69 age group to $2.2(0.13) \mathrm{ml} / \mathrm{min} / 1.73 \mathrm{~m}^{2} /$ year among those over 80 years $(\mathrm{p}<0.001)$. The association of age with rate of kidney function decline was essentially unchanged after multivariate adjustment.

\section{Annual Loss in eGFR by Sex/Race Subgroups}

The annual change in creatinine and $\mathrm{GFF}_{\text {crea }}$ was compared across subgroups defined by race and sex. The mean annual changes $( \pm S D)$ in creatinine were $0.01 \pm$ $0.07 \mathrm{mg} / \mathrm{dl}$ in white women, $0.02 \pm 0.11 \mathrm{mg} / \mathrm{dl}$ in black women, $0.002 \pm 0.06 \mathrm{mg} / \mathrm{dl}$ in white men and $0.006 \pm$ $0.63 \mathrm{mg} / \mathrm{dl}$ in black men $(\mathrm{p}<0.001)$. Rates of eGFR change by sex and race subgroups are shown in figure 2 . After multivariate adjustment, female sex was associated 


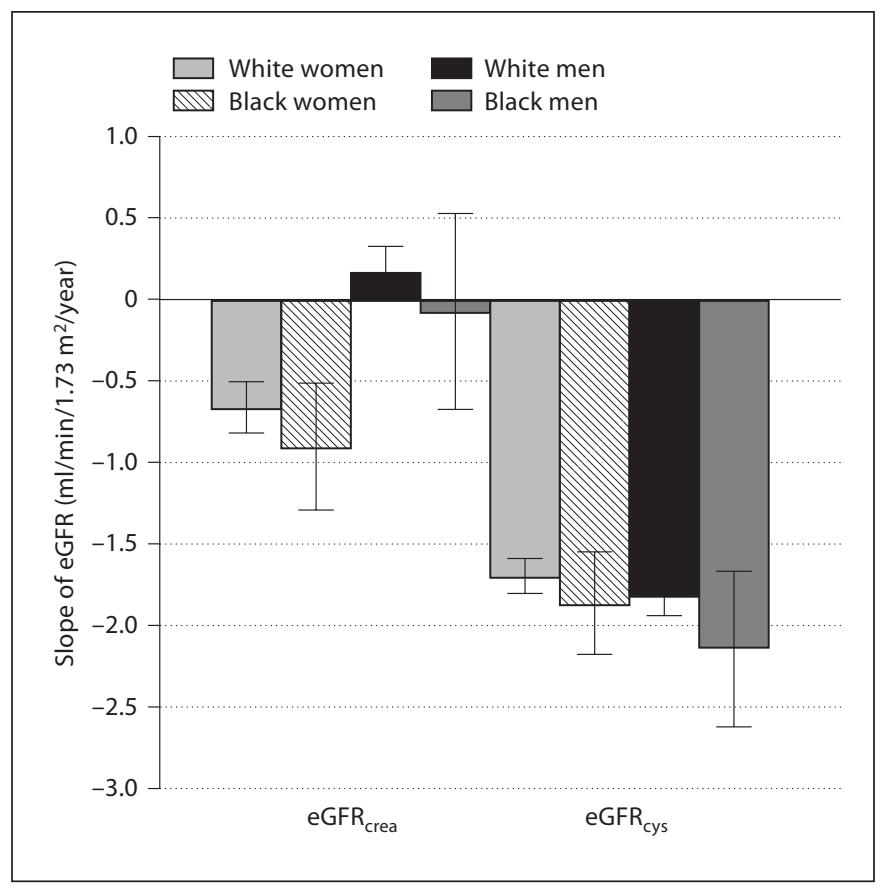

Fig. 2. Mean annual loss of kidney function by sex and race group. The panels on the left side present the annual eGFR declines using a creatinine equation; the panels on the right utilize a cystatin Cbased equation.

with a $0.5 \mathrm{ml} / \mathrm{min} / 1.73 \mathrm{~m}^{2}$ greater annual decline in $e_{\text {GFR }}$ crea $(\mathrm{p}<0.001)$, but race was not a significant predictor $(\mathrm{p}=0.10)$. In contrast, annual loss of $\mathrm{eGFR}_{\text {cys }}$ did not differ significantly by sex or race, varying only from -1.7 $\pm 2.4 \mathrm{ml} / \mathrm{min} / 1.73 \mathrm{~m}^{2} /$ year in white women to $-2.1 \pm$ $3.5 \mathrm{ml} / \mathrm{min} / 1.73 \mathrm{~m}^{2} /$ year in black men (fig. 2). Multivariate adjustment for age, risk factors and baseline kidney function decreased these differences: $-1.8 \mathrm{ml} / \mathrm{min} / 1.73$ $\mathrm{m}^{2} /$ year (95\% CI: $\left.-1.9,-1.6\right)$ for white women, $-1.7 \mathrm{ml} /$ $\mathrm{min} / 1.73 \mathrm{~m}^{2} /$ year $(95 \% \mathrm{CI}:-2.0,-1.3)$ for black women, $-1.9 \mathrm{ml} / \mathrm{min} / 1.73 \mathrm{~m}^{2} /$ year $(95 \% \mathrm{CI}: 2.1,-1.7)$ for white men and $-1.9 \mathrm{ml} / \mathrm{min} / 1.73 \mathrm{~m}^{2} /$ year $(95 \% \mathrm{CI}$ : $-2.4,-1.4)$ for black men. The adjusted rate of change in cystatin $\mathrm{C}$ concentration was $0.03 \mathrm{mg} / \mathrm{l} / \mathrm{year}$ in all 4 subgroups. The annual rate of change in 100/cystatin $\mathrm{C}$ ranged from -1.9 \pm 2.7 in white women to $-2.4 \pm 3.9$ in black men $(\mathrm{p}>$ $0.20)$.

\section{Age, Sex and Race as Predictors of Rapid Kidney}

Decline

A rapid rate of decline was observed in 714 (16\%) participants based on eGFR $\mathrm{Crea}_{\text {and }}$ 1,083 (25\%) participants based on eGFR $\mathrm{Cys}_{\text {s }}$. We compared the overlap of partici- pants with rapid decline by eGFR $\mathrm{crea}_{\text {and }}$ a GFR cys (fig. 3). Rapid decline by eGFR $\mathrm{R}_{\text {crea }}$ detected $39 \%$ of the 1,083 participants with rapid decline by $\mathrm{eGFR}_{\text {cys. }}$. Conversely, rapid decline by eGFR $_{\text {cys }}$ detected $59 \%$ of the 714 participants with rapid eGFR crea decline. The mean eGFR $\mathrm{eGFR}_{\text {cys }}$ declines were 5.8 and $1.0 \mathrm{ml} / \mathrm{min} / 1.73 \mathrm{~m}^{2} /$ year in

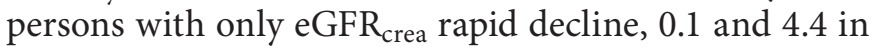

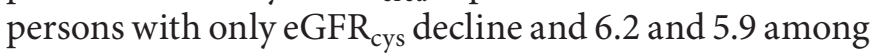
participants with rapid decline by both measures.

After multivariate analysis, increased age was strongly and incrementally associated with rapid decline in kidney function based on either eGFR $\mathrm{Crea}_{\text {rea }}$ eGFR $\mathrm{Gys}_{\text {(table }}$ 2 ). Race was not a predictor in either analysis. In the $\mathrm{eGFR}_{\text {crea }}$ analysis, men had only half the risk of women for rapid kidney decline, whereas sex was not associated with rapid kidney decline based on $\mathrm{eGFR}_{\text {cys }}$.

\section{Incident CKD by Creatinine and Cystatin $C$}

Among participants without CKD (eGFR $>60 \mathrm{ml}$ / $\mathrm{min} / 1.73 \mathrm{~m}^{2}$ ) at the initial visit, we compared the proportion who developed incident CKD $(e G F R<60)$ at the final kidney function measurement (year 7). Using eGFR ${ }_{\text {crea }}$, $10 \%(n=263)$ had developed CKD at the year 7 measurement of kidney function. The proportion with new CKD was nearly 2 -fold when measured by cystatin $\mathrm{C}$, making up $19 \%$ of the participants ( $\mathrm{n}=544, \mathrm{p}<0.001$ for dif-

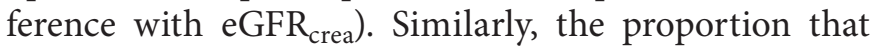
reached eGFR $<45$ was twice as high when kidney function was measured by cystatin C; making up $2 \%$ of the participants $(n=50)$ by eGFR $R_{\text {crea }}$ versus $4 \%(n=103)$ by $\mathrm{eGFR}_{\text {cys }}(\mathrm{p}<0.001)$. We also compared eGFR crea and 
Table 2. Association of age, sex and race with rapid decline in kidney function in the elderly

\begin{tabular}{|c|c|c|c|c|c|c|}
\hline & \multicolumn{3}{|c|}{$\Delta \mathrm{eGFR}_{\text {crea }} \leq-3.01 \mathrm{ml} / \mathrm{min} / 1.73 \mathrm{~m}^{2}(\mathrm{n}=714)$} & \multicolumn{3}{|c|}{$\Delta \mathrm{eGFR}_{\mathrm{cys}} \leq-3.01 \mathrm{ml} / \mathrm{min} / 1.73 \mathrm{~m}^{2}(\mathrm{n}=1,083)$} \\
\hline & events & OR (95\% CI) & $\mathrm{p}$ value & events & OR $(95 \% \mathrm{CI})$ & $\mathrm{p}$ value \\
\hline \multicolumn{7}{|l|}{ Age } \\
\hline 65-69 years & 228 & 1.00 (ref.) & & 351 & 1.00 (ref.) & \\
\hline $70-74$ years & 232 & $1.59(1.28,1.97)$ & 0.002 & 383 & $1.38(1.16,1.65)$ & $<0.001$ \\
\hline 75-79 years & 153 & $2.00(1.56,2.57)$ & $<0.001$ & 220 & $1.62(1.31,1.99)$ & $<0.001$ \\
\hline$\geq 80$ years & 101 & $3.90(2.88,5.28)$ & $<0.001$ & 141 & $2.96(2.28,3.84)$ & $<0.001$ \\
\hline African-American & & $1.22(0.96,1.54)$ & 0.104 & & $1.19(0.97,1.45)$ & 0.11 \\
\hline Male sex & & $0.51(0.41,0.62)$ & $<0.001$ & & $1.02(0.87,1.21)$ & 0.80 \\
\hline
\end{tabular}

Odds ratios adjusted for prevalent cardiovascular disease and kidney risk factors (hypertension, diabetes, smoking, HDL, LDL, baseline kidney measure)

$\mathrm{eGFR}_{\text {cys }}$ with the combined endpoint of 'death or CKD'. Each $5 \mathrm{ml} / \mathrm{min} / 1.73 \mathrm{~m}^{2}$ lower eGFR $\mathrm{cys}_{\text {s }}$ had significantly higher adjusted odds $(1.29 ; 1.24-1.33)$ of the combined outcome. The association per $5 \mathrm{ml} / \mathrm{min} / 1.73 \mathrm{~m}^{2}$ lower $\mathrm{eGFR}_{\text {crea }}$ was significant, but weaker $(1.04 ; 1.02-1.06)$.

\section{Discussion}

In this community-based cohort of older individuals, we observed substantial differences in the rates of kidney function decline using creatinine versus cystatin $C$ based estimates of GFR. When using the Modification of Diet in Renal Disease creatinine equation, we observed an annual eGFR decline of only $0.4 \mathrm{ml} / \mathrm{min} / 1.73 \mathrm{~m}^{2}$ over 7 years of follow-up, far less than the expected rate of decline [1]. The rate of $\mathrm{eGFR}_{\text {crea }}$ decline was substantially greater in women than men. In contrast, the cystatin Cbased eGFR measure declined annually by $1.8 \mathrm{ml} /$ $\min / 1.73 \mathrm{~m}^{2}$, which was more than 4 -fold the rate of $\mathrm{eGFR}_{\text {crea }}$, and did not differ by sex or race. Increasing age independently predicted more rapid rates of both $\mathrm{eGFR}_{\text {crea }}$ and eGFR $\mathrm{cys}_{\text {c }}$ decline. The proportion of participants identified as 'rapid decliners' (annual loss of GFR $>3 \mathrm{ml} / \mathrm{min} / 1.73 \mathrm{~m}^{2}$ ) was $50 \%$ higher when using eGFR compared with eGFR $\mathrm{Grea}_{\text {a }}$, and eGFR $\mathrm{Gys}_{\text {cys }}$ detected twice the incidence of $\mathrm{CKD}$ during follow-up compared with eGFR $\mathrm{crea}_{\text {. }}$ Because participants with rapid kidney decline in this cohort had a higher mortality risk [8], we believe that eGFR changes detected by either creatinine or cystatin $\mathrm{C}$ are clinically meaningful.

The most striking finding from our study was how different the eGFR slopes were when based on creatinine or cystatin $\mathrm{C}$. We believe that the differences are most likely caused by creatinine's insensitivity for detecting relatively small changes in GFR in elderly persons. Creatinine generation decreases with age, and likely is even further reduced in persons with accelerated kidney function decline, as these individuals have greater impairments in diet and physical activity. Unfortunately, no study has directly measured GFR in a large cohort of elderly persons, much less repeat GFR measurements several times during follow-up. Therefore, we cannot conclude that either the creatinine or cystatin $\mathrm{C}$ measurements are more accurate. In the absence of such a study, clinical research (like clinical practice), must rely on indirect estimates of GFR using endogenous filtration markers. Our prior research comparing associations of creatinine and cystatin $\mathrm{C}$ with longitudinal outcomes suggests to us that cystatin $\mathrm{C}$ may have a greater 'signalto-noise ratio' than creatinine. In addition, a small cohort of persons with type-2 diabetes and normal GFR levels found that $\mathrm{GFR}_{\mathrm{cys}}$ changed over time in close proximity with measured iothalamate GFR, whereas eGFR crea depicted a falsely slow rate of decline [13]. Furthermore, the $\mathrm{eGFR}_{\text {crea }}$ rates of decline in our study were much lower than expected based on prior studies of the elderly $[1,2$, 4]. Hopefully a future study will measure GFR longitudinally in elderly persons to help us distinguish the relative accuracy and precision of creatinine and cystatin $\mathrm{C}$ in this population.

If our data are able to be generalized and cystatin C does capture unrecognized CKD, these results could have substantial public health importance. Based on NHANES 1999-2002, the elderly population (65+) in the United States was 36 million, of whom 28 million did not have CKD. Assuming 9\% develop unrecognized CKD during a 7-year follow-up, then 2.5 million (350,000/year) could 
be detected by serial measurements of cystatin C, but not creatinine. Whether or not this 'early detection' strategy would improve patient outcomes is a question for future research.

In this study, the association of sex with kidney function decline differed between analyses based on $\mathrm{eGFR}_{\text {crea }}$ and $e \mathrm{GFR}_{\text {cys; }}$; women had a greater decline in $\mathrm{GFR}_{\text {crea }}$ than men, but equivalent declines in $\mathrm{eGFR}_{\text {cys }}$. Although no prior studies have addressed this research question using cystatin C, 2 studies that used iothalamate GFR in CKD cohorts, the Modification of Diet in Renal Disease and the African-American Study of Kidney Disease and Hypertension studies, found no association of sex with progression $[21,22]$. Among studies that evaluated longitudinal changes in kidney function by creatinine-based measurements, 8 studies found no independent differences by sex, whereas 6 found a faster progression among men $[16,23,24]$. A sex-based comparison of the longitudinal associations of $\mathrm{eGFR}_{\text {cys }}$ declines with health outcomes would be helpful for determining the relative prognostic utility of cystatin $\mathrm{C}$ among men and women.

The incidence of ESRD in the United States is substantially higher among blacks of all ages compared with whites; yet black and white participants had similar rates of kidney function decline in this study, based on creatinine or cystatin $\mathrm{C}$. Although race did not predict rapid decline by either measurement, $\mathrm{eGFR}_{\mathrm{cys}}$ detected a greater proportion of black participants with rapid decline of kidney function. Two prior studies in non-CKD cohorts also found no association of race with kidney function decline $[25,26]$, whereas a study of nondiabetic CKD found a faster rate of progression among blacks [21]. A United States population analysis found that blacks and whites have a similar prevalence of CKD, but that blacks have faster progression from CKD to ESRD [27]. Future studies should evaluate whether the measurement of cystatin $\mathrm{C}$ adds useful information for understanding racial disparities in kidney disease.

This study has additional limitations beyond the absence of a 'gold standard' for GFR measurements. Many subjects in the CHS had only 1 measurement of kidney function as they died or were otherwise unable to provide adequate sera for a repeat measurement. The absence of these subjects could have biased our results toward an underestimate of kidney function decline by either measure, as the excluded subjects had higher baseline creatinine and worse comorbidity. Both GFR estimating equations used in this study were derived from cohorts that were predominately comprised of nonelderly persons with CKD $[12,28]$. At this time, we do not have GFR es- timating equations that have been validated in either elderly persons or in populations without kidney disease. However, the observed differences in $\mathrm{GGFR}_{\text {crea }}$ and $\mathrm{eGFR}_{\text {cys }}$ in this study are attributable to the much larger relative change over time in cystatin $\mathrm{C}$ compared with creatinine. Furthermore, less than $15 \%$ of our cohort was African-American, and we did not have any Asian or Hispanic participants.

In conclusion, GFR estimates from cystatin C indicated a more than 4 -fold rate of decline and a 2 -fold incidence of CKD compared with creatinine-based estimates. We also found twice the annual rate of GFR decline in elderly persons than had been reported in prior literature. Given the growing burden of CKD and ESRD, determination of the optimal method for GFR estimation in the elderly, whether by creatinine, cystatin $\mathrm{C}$ or a combination of both, should be a high priority for future research.

\section{Acknowledgements}

This work was supported by contracts R01 HL073208-01 and R01 DK066488 from the National Heart, Lung and Blood Institute (NHLBI) and the National Institute of Diabetes and Digestive and Kidney Diseases, respectively. In addition, this work was supported by the American Federation for Aging Research by a Paul Beeson Scholars Program award and R01AG027002 and K24DK078204-01 from the National Institutes of Health. The CHS is supported by contracts N01-HC-85079 through N01-HC85086, N01-HC-35129, and N01 HC-15103 from the NHLBI. This study was funded through contracts with the NHLBI and included substantial NHLBI involvement in data collection, analysis and interpretation, as well as manuscript preparation. A full list of participating CHS investigators and institutions can be found at http://www.chs-nhlbi.org.

References

1 Lindeman RD, Tobin J, Shock NW: Longitudinal studies on the rate of decline in renal function with age. J Am Geriatr Soc 1985;33: 278-285.

2 Ix JH, Shlipak MG, Chertow GM, Whooley MA: Association of cystatin C with mortality, cardiovascular events, and incident heart failure among persons with coronary heart disease: data from the Heart and Soul Study. Circulation 2007;115:173-179.

- 3 Jernberg T, Lindahl B, James S, Larsson A, Hansson LO, Wallentin L, Cystatin C: A novel predictor of outcome in suspected or confirmed non-ST-elevation acute coronary syndrome. Circulation 2004; 110:23422348. 
-4 Koenig W, Twardella D, Brenner H, Rothenbacher D: Plasma concentrations of cystatin $\mathrm{C}$ in patients with coronary heart disease and risk for secondary cardiovascular events: more than simply a marker of glomerular filtration rate. Clin Chem 2005;51:321-327.

$\checkmark 5$ Sarnak MJ, Katz R, Stehman-Breen CO, Fried LF, Jenny NS, Psaty BM, Newman AB, Siscovick D, Shlipak MG: Cystatin-C as a risk factor for heart failure in older adults. Ann Intern Med 2005;142:497-505.

-6 Shlipak MG, Sarnak M, Katz R, Fried LF, Seliger SL, Newman AB, Siscovick DS, Stehman-Breen CO: Cystatin-C and risk for mortality and cardiovascular disease in elderly adults. N Engl J Med 2005;352:20492060.

7 Shlipak MG, Wassel Fyr CL, Chertow GM, Harris TB, Kritchevsky SB, Tylavsky FA, Satterfield S, Cummings SR, Newman AB, Fried LF: Cystatin $C$ and mortality risk in the elderly: the health, aging, and body composition study. J Am Soc Nephrol 2006;17:254261.

8 Rifkin D, Shlipak MG, Katz R, Fried L, Siscovick DS, Chonchol M, Newman AB, Sarnak MJ: Rapid kidney function decline and mortality risk in older adults. Arch Intern Med 2008;168:2212-2218.

-9 Fried LP, Borhani NO, Enright P, et al: The Cardiovascular Health Study: design and rationale. Ann Epidemiol 1991;1:263-276.

-10 Tell GS, Fried LP, Hermanson B, Manolio TA, Newman AB, Borhani NO: Recruitment of adults 65 years and older as participants in the Cardiovascular Health Study. Ann Epidemiol 1993;3:358-366.

-11 Erlandsen EJ, Randers E, Kristensen JH: Evaluation of the Dade Behring N Latex Cystatin $\mathrm{C}$ assay on the Dade Behring Nephelometer II System. Scand J Clin Lab Invest 1999;59:1-8.

-12 Stevens L, Coresh J, Schmid CH, Feldman HI, Froissart M, Kusek J, Rossert J, Van Lente F, Bruce RD 3rd, Zhang YL, Greene T, Levey AS: Estimating GFR using serum cystatin C alone in combination with serum creatinine: a pooled analysis of 3,418 individulas with CKD. Am J Kidney Dis 2008;51:395-406.
13 Perkins BA, Nelson RG, Ostrander BE, Blouch KL, Krolewski AS, Myers BD, Warram JH: Detection of renal function decline in patients with diabetes and normal or elevated GFR by serial measurements of serum cystatin $\mathrm{C}$ concentration: results of a 4 -year follow-up study. J Am Soc Nephrol 2005;16 1404-1412.

14 Levey AS, Bosch JP, Lewis JB, Greene T, Rogers N, Roth D: A more accurate method to estimate glomerular filtration rate from serum creatinine: a new prediction equation. Modification of diet in renal disease study group. Ann Intern Med 1999;130:461-470.

15 Shlipak MG, Fried LF, Cushman M, Manolio TA, Peterson D, Stehman-Breen C, Bleyer A, Newman A, Siscovick D, Psaty B: Cardiovascular mortality risk in chronic kidney disease: comparison of traditional and novel risk factors. JAMA 2005;293:1737-1745.

16 Eriksen BO, Ingebretsen OC: The progression of chronic kidney disease: a 10-year population-based study of the effects of gender and age. Kidney Int 2006;69:375-382.

17 Klein R, Klein BE, Moss SE, Cruickshanks KJ, Brazy PC: The 10-year incidence of renal insufficiency in people with type 1 diabetes. Diabetes Care 1999;22:743-751.

-18 Perkins BA, Ficociello LH, Ostrander BE, Silva KH, Weinberg J, Warram JH, Krolewski AS: Microalbuminuria and the risk for early progressive renal function decline in type 1 diabetes. J Am Soc Nephrol 2007; 18: 1036-1037.

19 Sidak Z: Rectangular confidence regions for the means of multivariate normal distributions. J Am Stat Assoc 1967;62:626-633.

20 Go AS, Chertow GM, Fan D, McCulloch CE Hsu CY: Chronic kidney disease and the risks of death, cardiovascular events, and hospitalization. N Engl J Med 2004;351: 1296-1305.
21 Hunsicker LG, Adler S, Caggiula A, England BK, Greene T, Kusek JW, Rogers NL, Teschan PE: Predictors of the progression of renal disease in the Modification of Diet in Renal Disease Study. Kidney Int 1997;51: 1908-1919.

-22 Wang X, Lewis J, Appel L, Cheek D, Contreras G, Faulkner M, Feldman H, Gassman J, Lea J, Kopple J, Sika M, Toto R, Greene T: Validation of creatinine-based estimates of GFR when evaluating risk factors in longitudinal studies of kidney disease. J Am Soc Nephrol 2006;17:2900-2909.

$\checkmark 23$ National Kidney Foundation: K/DOQI Clinical Practice Guidelines for Chronic Kidney Disease: Evaluation, classification, and stratification. Kidney Disease Outcome Quality Initiative. Am J Kidney Dis 2002;39:S1S266.

-24 Hemmelgarn BR, Zhang J, Manns BJ, Tonelli M, Larsen E, Ghali WA, Southern DA, McLaughlin K, Mortis G, Culleton BF: Progression of kidney dysfunction in the community-dwelling elderly. Kidney Int 2006; 69:2155-2161.

25 Shulman NB, Ford CE, Hall WD, Blaufox MD, Simon D, Langford HG, Schneider KA: Prognostic value of serum creatinine and effect of treatment of hypertension on renal function: results from the hypertension detection and follow-up program. The Hypertension Detection and Follow-up Program Cooperative Group. Hypertension 1989;13: I80-I93.

26 Walker WG: Hypertension-related renal injury: a major contributor to end-stage renal disease. Am J Kidney Dis 1993;22:164-173.

27 McClellan WM, Langston RD, Presley R: Medicare patients with cardiovascular disease have a high prevalence of chronic kidney disease and a high rate of progression to end-stage renal disease. J Am Soc Nephrol 2004;15:1912-1919.

-28 Levey AS, Bosch JP, Lewis JB, Greene T, Rogers N, Roth D: A more accurate method to estimate glomerular filtration rate from serum creatinine: a new prediction equation. Modification of Diet in Renal Disease Study Group. Ann Intern Med 1999;130:461-470. 